\title{
Massa marginal na América Latina: mudanças na conceituação e enfrentamento da pobreza 40 anos após uma teoria
}

| ${ }^{1}$ Hayda Alves, ${ }^{2}$ Sarah Escorel I

Resumo: As abordagens e expressões da questão social como pobreza envolvem discussóes acerca da configuração e do enfrentamento de fraturas sociais, vinculadas ao processo de reestruturação produtiva capitalista, em diversas dimensōes: econômicas, políticas, culturais e sociais. O objetivo do artigo é rever esse debate, passados 40 anos da teoria de marginalidade latino-americana, que inaugurou um olhar específico sobre a pobreza a partir da tese de massa marginal de Jose Nun. Ao longo desse período, são destacadas singularidades dos olhares sobre a pobreza como questão social na América Latina e a aproximação com os teóricos franceses da exclusão social. Após a década de 1990, observa-se o direcionamento do debate na perspectiva teórica da exclusão social, operacionalizada como uma categoria capaz de revelar processos de fragilização e ruptura da coesão social a partir de múltiplos níveis e dimensôes relacionais.

> Palavras-chave: pobreza; iniquidade; ciências sociais.
1 Doutoranda em Saúde Pública (Escola Nacional de Saúde Pública Sergio Arouca da Fundação Oswaldo Cruz; professora assistente, Curso de graduação em Enfermagem, Polo Universitário de Rio das Ostras (Universidade Federal Fluminense). Endereço eletrônico: haydaenf@gmail.com

${ }^{2}$ Médica sanitarista; doutora em Sociologia (UnB), pesquisadora titular (Ensp/ Fiocruz). Endereço eletrônico: sescorel@ensp.fiocruz.br

Recebido em: 12/01/2011. Aprovado em: 11/09/2011. 


\section{Introdução}

Diversos autores, especialmente de filiação marxista, destacam que a questão social é indissociável do processo de acumulação capitalista, sendo produto das contradições existentes entre a concentração de riqueza das classes dominantes e a exploração da força de trabalho. O desenvolvimento dessa forma de produção teve como repercussão social o aumento da pobreza generalizada, em especial, da classe trabalhadora (NETTO, 2001; IAMAMOTO, 2001).

A partir de meados dos anos 1970, a questão social adquiriu outras expressōes. A crise da sociedade salarial e a ampliação do desemprego estrutural no esgotamento da chamada Era de Ouro do Pós-Segunda Guerra Mundial fizeram emergir o que foi denominada uma nova pobreza (ROSANVALLON, 1998; CASTEL, 2008). Esta é resultante das transformações na economia política do capitalismo com desdobramentos nos processos de trabalho, hábitos de consumo, configurações geopolíticas, poderes e práticas dos Estados nacionais (HARVEY, 2009). Nesse cenário, as análises sobre o crescimento da pobreza referem-se às repercussões da crise do modelo desenvolvimentista na América Latina e do colapso dos sistemas de welfare state nos países desenvolvidos (UGÁ, 2004; IVO, 2008).

Dessa forma, a expressão da pobreza na cena pública adquire novas conotações ideológicas e de intervenção por parte do Estado, singularizadas a partir de distintos modelos interpretativos nos Estados Unidos, na América Latina e na Europa (KOWARICK, 2003). Enquanto na América Latina os estudos sobre marginalidade ganham força, triunfou nos Estados Unidos, por volta da década de 1960, um pensamento conservador condenatório acerca da pobreza e dos pobres que habitavam os guetos, classificados como componentes de um novo grupo social: underclass (MARKS, 1991; KOWARICK, 2003).

Já na França, as discussões sobre a responsabilização do Estado frente à pauperização gerada pela crise da sociedade salarial, com a implosão do pleno emprego e do sistema de welfare state, a partir do final dos anos de 1970 e do início de 1980, fizeram emergir as discussões sobre a nova pobreza que endossaram as teorias da exclusão social (DONZELOT, 1991; CASTEL, 1991; 2008).

A partir da década de 1990, o enfrentamento da pobreza ganha centralidade no âmbito das políticas públicas em dimensão global como um problema inaceitável ao desenvolvimento do capitalismo no final do século XX. Aliadas a esse debate, as estratégias de combate à pobreza corporificam, a partir de então, uma nova 
institucionalidade das políticas sociais, que passam a ser direcionadas pelas orientações das agências internacionais. Isso ocorre em função do papel decisivo das mesmas para financiamento de ações de caráter nacional para a redução da pobreza, especialmente entre os países da América Latina (UGÁ, 2004; 2008).

Passados 40 anos da teoria da marginalidade latino-americana, o objetivo deste trabalho é analisar as mudanças na conceituação de pobreza urbana. Ao longo desse período, verifica-se que o debate foi redefinido na perspectiva teórica da exclusão social. O enfrentamento da exclusão, mesmo implícito em estratégias institucionais globais endereçadas aos problemas sociais contemporâneos, foi direcionado para a elaboração de políticas públicas voltadas ao combate à pobreza em uma perspectiva multidimensional.

\section{Marginalidade: o debate originado na América Latina}

A literatura recente que emprega o termo marginaldade (WACQUANT, 1999; 2008; PENÂ, 2005; WATT, 2003; LEE, WONG, LAW, 2007) não o vincula diretamente à produção acadêmica latino-americana do final da década de 1960, a qual contextualizava o debate em uma perspectiva crítica, de orientação marxista, sobre o cenário de pauperização gerado pela modernização do processo produtivo capitalista em países periféricos, com a precarização do trabalho e a formação de grandes contingentes de exército industrial de reserva (NUN, 1969; QUIJANO, 1973). A utilização do termo nessa perspectiva caiu em desuso tanto por seu abandono como teoria interpretativa da pobreza, quanto pela emergência de novos conceitos e critérios de intervenção pública, ligados à globalização e à reestruturação produtiva em escala mundial (UGÁ, 2008).

Apesar das interpretações acerca da pobreza urbana presentes nos estudos sobre marginalidade convergirem nas críticas às fraturas sociais resultantes do capitalismo contemporâneo, as perspectivas teóricas se distanciam pela filiação do "novo regime de marginalidade urbana" (WACQUANT, 1999) ao enfoque socioantropológico de tratamento da pobreza a partir de sua configuração socioespacial, étnico-racial e de segregação intimamente ligada à violência urbana, dificultando, desse modo, a plena integração social (WATT, 2003; PENÃ, 2005; LEE; WONG; LAW, 2007; ZALUAR, 1985; 2004; WACQUANT, 2008).

Escorel (1999, p. 39) destaca que, em todas "as abordagens do fenômeno da marginalidade, o aspecto relacional e relativo da oposição centro/periferia 
é mantido"; no entanto, o que muda são valores, comportamentos, atitudes, localização espacial e posição no sistema produtivo.

Segundo Lúcio Kowarick (1985), após a Segunda Guerra Mundial, a marginalidade urbana apareceu como importante problema teórico e prático. As primeiras abordagens ao tema eram de cunho "físico-ecológico" e centravamse na análise da precariedade habitacional. Posteriormente, acrescentou-se uma gama de interpretaçôes acerca das condições socioeconômicas e culturais que caracterizavam as populaçóes residentes em áreas de pobreza.

A segunda abordagem, hegemônica entre os estudiosos latino-americanos, centrava-se em duas correntes de pensamento: sociocultural-funcionalista e histórico-estrutural. A primeira privilegiava a integração social como expressão da dualidade da estrutura social (marginal/integrado); a segunda analisava a marginalidade sob o prisma das relaçôes sociais de produção, dada a inserção marginal dos trabalhadores no processo produtivo, evidenciada pela emergência do desemprego e da subocupação.

José Nun (1969) foi importante expoente do pensamento histórico-estrutural nos estudos sobre marginalidade e pioneiro ao tratar o tema como um conceito relativo ao lugar ocupado por determinados grupos sociais na esfera produtiva. Em uma perspectiva crítica de recorte marxista, Nun denunciou a formação de uma "subclasse" dentro do proletariado latino-americano composta pelo (i) exército industrial de reserva, população excedente de trabalhadores à disposição do capitalismo, com possibilidade de incorporação ao processo produtivo, e pela (ii) superpopulação relativa, constituída pela população que excede os limites da incorporação do sistema produtivo.

Os meios de produção, e não os meios de subsistência, são os que fazem os trabalhadores ingressar na categoria de superpopulação. Nun sublinhou, ainda, a existência de um contingente populacional que não interessava ao mercado, constituindo-se na parte afuncional ou disfuncional do exército industrial de reserva.

Partindo do conceito de Nun (1969), Aníbal Quijano (1978) contribuiu para o debate sobre "informalidade" no trabalho, ao definir como "polo marginal" o conjunto de ocupações ou atividades estabelecidas geralmente em torno do uso de recursos residuais, ou desligadas da produção, de caráter disfuncional ao sistema de acumulação capitalista. Quijano ampliou a discussão da tese de massa marginal ao problematizar a realidade carencial crescente no tecido social urbano. 
Aderindo em grande medida à perspectiva teórica de Nun e Quijano, o sociólogo

brasileiro Lúcio Kowarick (1985) estudou a marginalidade urbana, destacando para seu delineamento o pauperismo e o cenário de favelização; a estratificação econômico-ocupacional inferior, dificuldades enfrentadas pelas minorias raciais e étnicas nos grandes centros urbanos; além do êxodo rural, compreendido como fenômeno migratório gerador de uma perversa marginalidade cultural. Os estudos de Kowarick evidenciaram que o nível de marginalidade variava de parcial a generalizada em função da precariedade do vínculo à sociedade urbana.

A integração dos trabalhadores de maneira marginal, como exército industrial de reserva, ou ainda de forma precária e desigual às engrenagens produtivas do capitalismo, também foi objeto de análise de Berlink (1975) no trabalho Marginalidade social e relaçôes de classe em São Paulo. Kowarick (1985) e Berlink (1975) questionavam a perda de clareza conceitual e analítica do termo marginalidade, que rapidamente havia acolhido uma variedade de situações e problemas vivenciados pela população pobre à margem das sociedades urbanoindustriais. Nesse sentido, defendiam a utilização do termo na perspectiva do estruturalismo histórico, de modo a especificar a inserção ou não dos trabalhadores no processo produtivo capitalista (MAIOLINO; MANCEBO, 2005).

Contrariamente, em trabalho mais recente, Nun (2000) destaca que sua análise e a de seus colaboradores sobre a massa marginal não foi centrada nos "trabalhadores sem trabalho", nem no plano teórico nem no campo das pesquisas empíricas, mas de fato objetivava: (i) enfatizar a relação estrutural entre o processo de acumulação capitalista que prevaleceu na América Latina e os fenômenos da pobreza e da desigualdade social, em contraste com as tendências interpretativas da "cultura da pobreza" (LEWIS, 2006), que responsabilizavam os pobres por sua condição; (ii) destacar a fragmentação e a heterogeneidade crescente da estrutura ocupacional da América Latina e suas consequências na formação de identidades sociais; e (iii) chamar a atenção tanto para a disfuncionalidade da população excedente ao capitalismo, como também para os mecanismos de dualização e segregação remanescentes de uma conjuntura histórica passada, cujas expressões ainda marcam o presente.

Apesar da importância histórica da teoria da marginalidade, essa matriz explicativa foi abandonada em virtude da emergência do conceito de exclusão social para enunciar e tratar a expressão contemporânea da questão social 
em escala global, a qual analisa o fenômeno para além da dualidade de um polo social marginal versus integrado, relacionando-o a mudanças culturais, políticas e econômicas vinculadas aos processos de globalização e reestruturação produtiva que deram origem a uma "nova pobreza" (ROSANVALLON, 1998). Provavelmente, a teoria da marginalidade também foi relegada pelos limites geográficos das análises latino-americanas, tanto em função de uma possível barreira linguística, quanto pelo desinteresse dos países centrais em discutir teorias acerca de um problema que os afligia em uma escala muito menor, ou apenas em caráter residual, diferentemente do caráter histórico da pobreza de massa nos países latino-americanos.

\section{Underclass e Exclusão Social como categorias de pobreza: singularidades e influências no debate latino-americano}

Although it is not always acknowledged, the Latin American debate on marginality foreshadowed the current concerns with social exclusion. ${ }^{1}$

(KAY, 2006, p. 460)

Durante a década de 1960, as explicações sobre o pauperismo adquiriram forte conotação ideológica nos EUA, classificando o pobre em uma subcategoria: a underclass, a qual compreendia a população expelida por um tipo de "darwinismo social", que premia com o sucesso os trabalhadores competitivos, geralmente brancos, e pune os pobres "passivos", os "desqualificados", geralmente afro-americanos.

O debate incluía os que defendiam a responsabilização individual pela situação de pobreza, os que acreditavam que a categoria era formada por vítimas de suas próprias atitudes, e os que consideravam os pobres como vítimas de forças sociais e econômicas as quais demandavam políticas públicas de combate à pobreza urbana - uma responsabilidade parcial do Estado (MARKS, 1991; KOWARICK, 2003).

Segundo Wacquant (1996), o termo surgiu a partir dos trabalhos do economista sueco Gunnar Myrdal entre 1962 e 1963, em meio ao otimismo da economia norte-americana, para designar "famílias e indivíduos subempregados, sem emprego e gradualmente inimpregáveis, situados no mais baixo da escala social” (ESCOREL, 1999, p. 45). 
Carole Marks (1991), ao revisar o conceito de "urban underclass", destaca o mosaico de categorias sociais que o compõe a partir das definições empregadas em revistas das décadas de 1970 e 1980 (Newsweek, Fortune, Reader's Digest), incorporando questôes de raça, gênero, emprego e estrutura familiar. Uns destacavam a underclass como sendo constituída por indivíduos sem formação, habilidade, experiência profissional, ou, ainda, por desempregados de longa duração ou excluídos do mercado de trabalho. Outros afirmavam que o grupo incorporava preponderantemente indivíduos pobres e sem instrução escolar, homens jovens de 14 a 27 anos, adolescentes grávidas solteiras e pessoas dependentes de auxílio financeiro do Estado.

Citando Ken Auletta (1982), Marks (1991) destaca quatro elementos definidores da categoria underclass: hostilidade das ruas, carreira criminosa, dependência de apoio governamental e indivíduos gravemente traumatizados.

A segregação implícita na categoria urban underclass tinha duas bases importantes: racial (KOWARICK, 2003) e socioespacial (GREENE, 1991). Para Greene (1991), a concentração territorial da pobreza em determinados pontos da cidade poderia favorecer o isolamento social, influenciar o comportamento e limitar as oportunidades de trabalho e de educação, entre outros aspectos da vida.

As estratégias de enfrentamento da pobreza nos Estados Unidos, nas décadas de 1960 e 1970, por meio do que ficou conhecido como "war on poverty", constituído por programas sociais como o "Aid To Families With Dependent Children”, eram criticadas sob as alegaçóes de: favorecer a dependência dos pobres aos benefícios estatais; estimular a desobrigação com o desenvolvimento econômico da sociedade; e incitar comportamentos "ilegais", como querer permanecer desempregado ou tornar-se mãe solteira, entre outros. Essas estratégias demandavam, portanto, políticas que exigissem contrapartidas obrigaçõos sociais de cidadania (KOWARICK, 2003).

Sob diversas perspectivas, os valores implícitos na denominação "underclass" podem ser considerados uma forma de expressão do pensamento conservador norte-americano, tanto no que se refere à individualização da responsabilidade por uma situação social, quanto nas críticas relacionadas à mediação e à intervenção institucional do Estado endereçadas ao combate da pobreza. Nesse caso, aos desqualificados que compóem outra classe social abaixo dos pobres, a underclass, uma subclasse. 
A partir de 1980, com a persistência dos efeitos da crise do petróleo de 1973 e os processos de reestruturação produtiva, a pobreza, até então residual nos países desenvolvidos, ganha amplitude em virtude da queda da taxa de lucro do capital, do baixo crescimento da produção e da produtividade com repercussões no mundo do trabalho, do crescente desemprego, da queda dos investimentos, do aumento do capital financeiro, e da aceleração geral dos preços com endividamento dos governos (HARVEY, 2009).

Os problemas sociais advindos da crescente precarização e vulnerabilidade da classe trabalhadora, bem como a fragmentação dos sistemas de proteção social fundados na sociedade salarial, enunciam uma nova expressão da questão social na Europa, explícita na emergência de "novos pobres", "novos excluídos”, desfiliados, sobrantes, inúteis ao mundo (DONZELOT, 1991; ROSANVALLON, 1998; CASTEL, 2008).

Nesse contexto, há uma metamorfose da questão social, como afirma Robert Castel (2008), a partir da crise da sociedade salarial, com a instabilidade ou a expulsão do emprego de grandes contingentes de trabalhadores, ocasionando mudanças na inserção relacional, fragilização dos suportes protetores, e um processo de isolamento social dos novos excluídos. Assim, os problemas sociais emergentes na "nova questão social" francesa foram enunciados como exclusão.

Diferentemente das antigas conotações do termo exclusão usadas para referenciar a situação de grupos marginalizados historicamente como handicapés sociaux (doentes mentais, alcoólatras, entre outros que deveriam beneficiar-se de políticas específicas de proteção social), a nova pobreza transformava em excluídos, desfiliados, desintegrados socialmente, pessoas de baixa qualificação em virtude da precarização econômica e social dos novos desempregados (handicapés légers) (DONZELOT, 1991; CASTEL, 2008).

Segundo Zioni (2006), o termo exclusão aparece pela primeira vez nas obras de Piérre Massé - Les dividendes du progrès, em 1960 - e L'exclusion sociale, de Jean Kanfler, em 1965. Em meados da década de 1970, René Lenoir deu maior visibilidade ao fenômeno da exclusão no universo discursivo e político francês a partir da obra Les exclus: un français sur dix, publicada em 1974 (ESCOREL, 1999; KOWARICK, 2003; LEAL, 2008). Ainda que a obra de Lenoir não contenha qualquer elaboração teórica do conceito de exclusão social, traz à tona um problema social que até então parecia ser residual e superável (ESCOREL, 1999). 
Robert Castel $(1991 ; 2008)$ inaugura uma matriz teórica para análise das mudanças da questão social. Nela, os processos de exclusão social passam a ser tratados a partir de dois eixos analíticos de integração e desfiliação: o mundo do trabalho e o mundo das relações sociofamiliares (ESCOREL, 1999).

O cruzamento de tais eixos origina quatro zonas: (i) zona da integração, na qual os indivíduos possuem trabalho estável e forte inserção relacional; (ii) zona de vulnerabilidade, que associa trabalho precário a manutenção dos apoios relacionais; (iii) zona da desfiliação, marcada pela ausência de participação em qualquer atividade produtiva e isolamento relacional; e (iv) zona da assistência social, circunscrita aos inaptos para o trabalho, inválidos de todo tipo, como idosos, doentes sem recursos, crianças abandonadas, miseráveis, entre outros, com frágil inserção social e dependentes de mecanismos e programas de assistência social.

Frente à densidade do conceito de exclusão social, Martine Xiberras (1996, p. 18-19; 33) destaca que

\begin{abstract}
os excluídos não são rejeitados apenas fisicamente (racismo), geograficamente (gueto) ou materialmente (pobreza). Eles não são simplesmente excluídos das riquezas materiais, isto é, do mercado e da sua troca [...] são excluídos também das riquezas espirituais: seus valores não são reconhecidos e são ausentes ou banidos do universo simbólico. Logo que começam a aparecer, esses valores figuram decisivamente nas representaçôes coletivas, mas numa forma inversa: [...] atributos negativos que os classifica na categoria do estigma [...]. A exclusão pode ser visível e materializada através de comportamentos e atitudes de evitação, desconfiança, rejeição, ódio, como também pode assumir formas dissimuladas de ruptura de vínculo social.
\end{abstract}

Xiberras (1996) analisa o conceito de coesão social em Durkheim, Simmel e Weber, e as teorias do desvio (Becker) e estigma (Goffman) da Escola de Chicago, e formula um conceito de exclusão social como um processo multidimensional configurado por rupturas dos vínculos sociais e simbólicos.

Serge Paugam (1997) destaca as transformações imputadas pela condição de exclusão na perspectiva da identidade social dos indivíduos e dos vínculos familiares, por meio de um processo denominado "desqualificação social". Na obra La desqualification sociale: essai sur la nouvelle pauvreté, realizada a partir de uma enquete com 70 pessoas na cidade francesa de Saint-Brieuc, localidade fortemente marcada pelo desemprego, o autor descreve o processo de desqualificação social iniciado pela fragilidade conferida por uma ruptura inicial, passando por quebras de novos laços sociais e encerrando-se na percepção de uma ausência de utilidade social e de sentidos atribuídos à vida pelo próprio indivíduo. 
Esse processo de desqualificação social se desdobra no âmbito do sujeito face aos serviços de assistência pública, permitindo distinguir três tipos segundo o momento no qual se encontram (PAUGAM, IBIDEM): fragilizados (situados no ponto de partida em virtude de desemprego, dificuldades de inserção profissional, perda de moradia etc., são sujeitos que mantêm distância dos serviços), assistidos (passaram do status de trabalhador e denotam dependência dos serviços) e marginalizados (momento no qual rompem com os vínculos sociais).

Véras (2003) destaca a importância das análises de Paugam, ao sinalizar que as políticas sociais tanto podem integrar os assistidos como estigmatizar as pessoas e pesar de forma negativa na construção de suas identidades.

Diversos autores como Robert Castel, Serge Paugam, Martine Xiberras, entre outros - os quais têm produzido estudos sobre exclusão social com pontos convergentes nas questóes relativas à fragilidade e à ruptura do laço social têm exercido grande influência na produção teórica internacional para além do cenário francês (LEAL, 2008).

O mesmo ocorreu entre os autores brasileiros após a década de 1990 (ESCOREL, 1999; OLIVEIRA, 1997; OLIVEIRA, 2001; WANDERLEY, 2001). Estes discutem a especificidade do fenômeno da exclusão como resultado da precarização das relações de trabalho e das fragilidades do sistema de seguridade social no Brasil, haja vista, nesse país, a proteção social nunca ter alcançado a configuração de um welfare state a exemplo dos países europeus.

Para Escorel (1999, p. 81), o processo de exclusão social envolve trajetórias de vulnerabilidade, fragilidade ou precariedade, e até ruptura dos vínculos, considerando cinco dimensões da existência humana em sociedade: econômicoocupacional, sociofamiliar, política, cultural e da vida. Assim, no fim do processo, quando se configura um estado de exclusão social, este

se caracteriza não só pela extrema privação material, mas, principalmente, porque esta mesma privação material "desqualifica" seu portador, no sentido de que lhe retira a qualidade de cidadão, de brasileiro (nacional), de sujeito e de ser humano, de portador de desejos, vontades e interesses legítimos que o identificam e diferenciam.

Para a autora, a compreensão da categoria exclusão social como um estado e um processo possibilita

perceber a heterogeneidade das histórias de vida de pessoas que, no limite, na situação polar negativa, na condição de excluído, são jogadas numa 'vala comum' que homo- 
No limite da condição de excluído, ao fim de um processo de ruptura dos vínculos nas diferentes dimensões, a autora identifica uma gama de situações de não pertencimento social, de não suprimento das necessidades vitais e de limites à existência humana, resultando em formas de sobrevivência singulares e desumanizadoras, marcadas pela falta de suportes de vida estáveis, materiais e simbólicos. Dessa forma, o cotidiano dos excluídos é cercado por um misto de indiferença e hostilidade. Assim, a exclusão social é tanto um processo quanto um estado marcado por múltiplas formas de vulnerabilidade em diferentes dimensões.

Partindo da conceituação de Escorel, a SEKN - Social Exclusion Knowledge Network (POPAY et al., 2008), uma das nove redes de conhecimentos criadas pela Comissão de Determinantes Sociais da Saúde (CDSS) da Organização Mundial de Saúde (OMS), elaborou um modelo conceitual de exclusão social, visando à formulação de recomendações sobre as relações entre exclusão social e saúde.

Para a SEKN (POPAY et al., 2008, p. 36), a

exclusão consiste em processos dinâmicos e multidimensionais orientados por relações de poder desiguais. Tais processos operam conjuntamente e interativamente através de quatro dimensões (cultural, econômica, política e social) e em diferentes níveis, incluindo o nível individual, grupal, familiar, comunitário, nacional e regional global.

Essas dimensões relacionais são constructos analíticos que, na realidade social, das relações políticas, econômicas e culturais, estão interligados e se sobrepõem. Tais dimensões são utilizadas como instrumentos para auxiliar a compreensão dos processos de exclusão, para iluminar percursos entre esses processos, a saúde da população e as desigualdades de saúde e para prover um quadro de avaliação de políticas e ações visando à intervenção nesses processos. As característicaschave de cada dimensão são (POPAY et al., 2008, p.37):

I. Dimensão social: constituída por relaçôes proximais de apoio e solidariedade (amizade, família, comunidade, movimentos sociais) que geram um sentimento de pertença no âmbito dos sistemas sociais. Ao longo desta dimensão, os suportes podem ser enfraquecidos ou fortalecidos.

II. Dimensão política: constituída por uma dinâmica de poder nas relações as quais geram padrōes desiguais tanto nos direitos formais incorporados na legislação, constituições, políticas e práticas quanto nas condiçōes em que os direitos são exercidos - incluindo o acesso à água potável, saneamento, habitação, transporte, alimentação 
e serviços tais como saúde, educação etc. Ao longo desta dimensão, existe uma distribuição desigual de oportunidades para participar na vida pública, para expressar desejos e interesses, ou relacionadas ao acesso aos serviços.

III. Dimensão cultural: constituída pelas diversas formas em que valores, normas e modos de vida são aceitos e respeitados. Em um extremo ao longo desta dimensão, a diversidade é aceita em toda a sua riqueza, e, no outro, há situações extremas de estigma e discriminação.

IV. Dimensão econômica: constituída pelo acesso e distribuição material dos recursos necessários para sustentar a vida (renda, emprego, moradia, terra, condições de trabalho, meios de subsistência etc.).

As desigualdades em saúde podem ser analisadas a partir de um continuum de processos de inclusão/exclusão (POPAY et al., 2008, p. 37). Tal continuum é caracterizado por uma gama de situações injustas no que se refere à distribuição de recursos e a oportunidades para o desenvolvimento de capacidades e direitos. O enfrentamento das questôes torna-se imprescindível para a compreensão e a superação de um patamar de atendimento às necessidades básicas dos cidadãos. Dessa forma, visa impulsionar a participação e a coesão social, valorizar a diversidade, garantir a paz e os direitos humanos e manter ambientes sustentáveis.

O termo exclusão social é ainda objeto de crítica de diversos autores, que destacam:

- Banalização do termo pelo uso abusivo, de modo a expressar mais conteúdos ideológicos do que explicativos (PAUGAM, 1997; ZIONI, 2006);

- Fomento do esvaziamento da dimensão política da ação pública voltada à superação da pobreza e desigualdades (DEMO, 2002; 2003);

- Imprecisões como categoria analítica, vista a inclusão de grupos extremamente diversificados numa mesma categoria (trabalhadores, desempregados, doentes, etc.) (ZALUAR, 1997; MARTINS, 2003);

- Fetichização da ideia de exclusão e reducionismo interpretativo, de modo a mascarar as relações contraditórias entre o sistema produtivo capitalista e a sociedade, entre determinantes econômicos e os problemas sociais (MARTINS, 1997; DEMO, 2003);

- Uma categoria de equação binária (incluído/excluído) filiada aos estudos da antropologia estrutural de lógica classificatória, portanto inadequada para compreender todos os tipos de comunidades e processos sociais (ZALUAR, 1997);

- Uma categoria frágil para apreensão de situações de pertencimento e identidades comuns partilhadas entre os excluídos, acentuando ainda, a perda de $s t a-$ 
tus de um grupo social específico, a anulação política da classe trabalhadora e, por conseguinte, o enfraquecimento do seu poder de transformação enquanto grupo (MARTINS, 2008);

- Termo utilizado em decorrência da falta de uma teoria de classe social adequada para expressar as fraturas sociais produzidas pelo capitalismo na atualidade (MARTINS, 2008);

- Uma categoria conservadora, que toma como referência os integrados na sociedade do consumo, fragilizando a análise sobre os modos degradados de inserção social, inclusão marginal, precária e perversa (MARTINS, 2008).

Um dos maiores críticos da "exclusão social", José de Souza Martins (2008, p. 17), afirma que a utilização desse termo, para classificar as desigualdades sociais, evidencia um dos aspectos da crise da sociedade de classes. "Revela-nos que a classe operária já não está no centro das explicações e dos combates sociais dos que atuam politicamente através dos chamados movimentos populares".

Essa perspectiva adere à tese de que a perda relativa da centralidade da categoria trabalho (OFFE, 1994) impulsiona o deslocamento das conceituações sobre pobreza urbana para outras dimensões da vida, como demonstram os trabalhos de Castel (1991; 2008), Escorel (1999) e Popay et al. (2008).

Nesse sentido, o abandono da tese da massa marginal, como uma matriz explicativa da pobreza, deve-se ao seu limite para caracterizar as expressões da questão social na atualidade que conjuga a ampliação da desigualdade social, para além dos efeitos perversos do capitalismo na esfera do trabalho, com a exposição dos indivíduos às vulnerabilidades sociais resultantes de diversas desproteções sociais.

\section{Considerações finais}

Passados 40 anos de elaboração da Teoria da Marginalidade, verifica-se que a temática da pobreza retoma sua relevância tanto no debate acadêmico quanto no âmbito da formulação de políticas públicas na América Latina. No entanto, o tratamento da questão social como pobreza parece ser insuficiente para abranger os diferentes processos desencadeados pela privação material e simbólica, melhor compreendidos pela categoria exclusão.

Destacam-se, no entanto, a importância e a atualidade do termo marginalidade para designar a dimensão espacial da pobreza e a estigmatização 
do pobre, embora em uma perspectiva teórica distanciada da tese de massa marginal latino-americana (WACQUANT, 1999; 2008; PEÑA, 2005; WATT, 2003; LEE, WONG, LAW, 2007).

Exclusão social tem sido a categoria utilizada para compreender as expressões contemporâneas da questão social na atualidade, em uma perspectiva teórica mais ampla do que a enunciada inicialmente no debate francês, tanto por expressar as fraturas sociais advindas das mudanças no processo de acumulação capitalista, como por apontar os processos que impossibilitam o indivíduo de "realizar plenamente a condição humana [...], ser cidadão, ser/estar incluído numa comunidade, pertencer a uma Nação, ser protegido pela lei e pelo governo, ser membro de uma sociedade" (ESCOREL, 1993, p. 50).

Apesar das críticas endereçadas à categoria exclusão social, esta tem se mostrado importante na análise das expressões contemporâneas da questão social a partir do reconhecimento de novos problemas que afligem a sociedade, ao adotar uma perspectiva multidimensional e relacional conforme destacado por Popay et al. (2008), e, dessa forma, não limitar o exame do processo a um campo disciplinar ou corrente de pensamento, dada a complexidade de temas e atores que abrange.

A banalização da utilização do termo exclusão social e os possíveis limites explicativos da categoria sobre as expressões da questão social na atualidade indicam a necessidade de desenvolvimento dessa perspectiva teórica, de modo a problematizar os processos de fragilização e rupturas dos vínculos sociais, além de impulsionar sobre estes a ação pública. Por outro lado, a utilização corrente do termo aponta para um consenso: "a constatação da existência empírica do fenômeno e sua relevância em termos quantitativos e qualitativos" (ZIONI, 2006, p. 27).

De fato, os processos de exclusão partem, majoritariamente, da exposição dos sujeitos e grupos às vulnerabilidades econômicas e às precariedades da proteção social, expressões sociopolíticas do processo produtivo capitalista contemporâneo e seus efeitos na sociedade. No entanto, "o combate à exclusão não se reduz à dimensão econômica, que, apesar de ser a dimensão fundamental, não existe isolada do contexto sociocultural que a legitima e a reproduz" (FLEURY, 2007, p. 1422-1423).

Além de revelar a magnitude de determinantes econômicos, a categoria exclusão social amplia as possibilidades analíticas ao incorporar outras dimensões, como a desigualdade no usufruto de direitos sociais, a troca de 
valores simbólicos e culturais, a subjetividade, o status social, o papel das redes

de apoio social e de diversos atores, etc. Essa visão possibilita a reconstrução do debate de maneira reflexiva à complexidade dos problemas sociais para além do status do incluído versus o excluído.

Tomando a exclusão social como fenômeno a ser enfrentado por políticas públicas, distintos atores, esferas de governo, organismos internacionais e setores públicos e privados, Popay et al. (2008) enumeram as vantagens de análises baseadas na exclusão social: reconhecer a relação subjacente entre inclusão social e direitos humanos, possibilitando o desenvolvimento de medidas para a promoção e a proteção dos direitos, de modo a reverter os processos de exclusão e promover a coesão social; partir da diversidade/complexidade de processos de exclusão para priorizar os alvos de intervenção, bem como propiciar um debate público a fim de orientar a formação de políticas e o desenvolvimento de ações, e não apenas a melhoria das condiçôes experimentadas por grupos rotulados como "excluídos sociais" 2 .

\section{Agradecimentos}

Agradecemos ao Prof. Luiz Antônio de Castro Santos - IMS/UERJ, por suas valiosas contribuiçóes na análise da tese de massa marginal desenvolvida na parte inicial do artigo.

\section{Referências}

AULETTA, K. The Underclass, 1982 In: MARKS, C. The urban underclass. Annual Reviews of Sociology, v.17, p.445-466, 1991.

BERLINK, M.T. Marginalidade social e relaçôes de classes em São Paulo. Petrópolis: Vozes, 1975.152p.

CASTEL, R. As metamorfoses da questão social: uma crônica do salário. $7^{\text {a }}$ ed. Petrópolis: Vozes, 2008. 611p.

. De l'indigence à l'exclusion, la désaffiliation. In : DONZELOT, J. (dir.). Face à l'exclusion. Paris, Ed. Esprit, 1991.p.137-168.

DEMO, P. Charme da exclusão. 2ed. Campinas: Autores associados, 2002. 125p. . Pobreza da pobreza. Petrópolis: Vozes, 2003.

DONZELOT, J. Le social du troisième type. In: DONZELOT, J. (dir.). Face à l'exclusion. Paris: Éditions Esprit, 1991. p.15-39. 
ESCOREL, S. Exclusão social: fenômeno totalitário na democracia brasileira. Rev. Saúde \& Sociedade. São Paulo, v.2, n.1, p. 41-57, 1993. . Vidas ao léu: trajetórias de exclusão social. Rio de Janeiro: Fiocruz, 1999. 275p. _. Vivendo de teimosos: moradores de rua da cidade do Rio de Janeiro. In: BURSZTYN, M. (org.) No meio da rua: nômades, excluídos e viradores. Rio de Janeiro: Garamond, 2000, p. 139-171.

FLEURY, S. Pobreza, desigualdades ou exclusão? Ciênc. saúde coletiva. Rio de Janeiro, v.12, n.6, 2007, p. 1422-1425.

GREENE, R. Poverty concentration measures and the urban underclass. Economic Gergraphy, v.67, n.3, p.240-253, 1991.

HARVEY, D. Condição pós-moderna: uma pesquisa sobre as origens da mudança cultural. 18ed. São Paulo: Loyola, 2009. 349p.

HOBSBAWM, E.J. Era dos extremos. O breve século XX - 1914-1991. Rio de Janeiro: Cia. das Letras, 1995. 632p.

IAMAMOTO, M.V. A questão social no capitalismo. Temporalis, n. 3, p. 9-32, 2001.

IVO, A.B.L. Viver por um fio: pobreza e política social. São Paulo: Annablume, 2008. 258p. KAY, C. Rural poverty and development strategies in Latin America. Journal of Agrarian Change, v.6, n.4, p. 455-508, 2006.

KOWARICK, L. Capitalismo e marginalidade urbana na América Latina $4^{\mathrm{a}}$ ed. Rio de Janeiro: Paz e Terra,1985. 188p.

. Sobre a vulnerabilidade socioeconômica e civil: Estados Unidos, França e Brasil. Rev. bras. Ci. Soc. São Paulo, v.18, n.51, p.61-85. 2003.

LEAL, G.F. Exclusão social e rupturas dos laços sociais: análise crítica do debate contemporâneo. Tese [Doutorado em Sociologia] - Instituto de Filosofia e Ciências Humanas, Universidade Estadual de Campinas, Campinas, São Paulo, 2008.

LEE, K-M.; WONG, H.; LAW, K-Y. Social polarization and poverty in the global city: the case of Hong Kong. China Report, v.43, n.1, p.1-30, 2007.

LEWIS, O. Antropología de la pobreza: cinco familias. México: Fondo de Cultura Económica, 2006. 302p.

MAIOLINO, A.L., MANCEBO, D. Análise histórica da desigualdade: marginalidade, segregação e exclusão. Psicologia \& Sociedade, v.17, n.2, p.14-20, 2005.

MARKS, C. The urban underclass. Annual Reviews of Sociology, v.17, p.445-466, 1991.

MARTINS, J.S. A sociedade vista do abismo: novos estudos sobre exclusão, pobreza e classes sociais. 3ed. Petrópolis: Vozes, 2008. 228p.

MARTINS, J.S. Exclusão social e a nova desigualdade. São Paulo: Paulus, 1997.140p. 
NETTO, J.P. Cinco notas a propósito da "questão social". Temporalis, n.3, p.41-49, 2001.

NUN, J. Marginalidad y ostras cuestiones. Revista Latinoamericana de Ciencias Sociales, n.4, p.366-398, 1972.

NUN, J. Superoblación relativa, ejercito industrial de reserva y masa marginal. Revista Latinoamericana de Sociología, Santiago, v. 5, n. 2, p.180-225, 1969.

NUN, J. The end of work and the "Marginal Mass" Thesis. Latin American Perspectives, v.27, n.1, p.6-32, 2000.

OFFE, C. Capitalismo Desorganizado: transformações contemporâneas do trabalho e da política. São Paulo: Brasiliense, 1994. 322p.

OLIVEIRA, L. Os excluídos "existem"? Notas sobre a elaboração de um novo conceito. Revista Brasileira de Ciências Sociais, São Paulo, n.33, v.12, p.49-51, 1997.

OLIVEIRA. M.C. (org). Demografia da Exclusão Social. Campinas: Unicamp, 2001. 190p.

PAUGAM, S. La desqualification sociale: essai sur la nouvelle pauvreté. $4^{\mathrm{a}}$ Éd. Paris, Presses Universitaires de France, 1997. 256p.

PEÑA, S. Recent developments in urban marginality along Mexico's northern border Habitat International, v.29, n.2, p.285-301, 2005.

POPAY, J., ESCOREL, S., HERNÁNDEZ, M., JOHNSTON, H., MATHIESON, J., RISPEL, L. Understanding and Tackling Social Exclusion. Final Report to the WHO Commission on Social Determinants of Health from the Social Exclusion Knowledge Network, 2008. 207p.

QUIJANO, A. Notas sobre o conceito de marginalidade. In: PEREIRA, L. (Org.). Populaçôes marginais. São Paulo: Duas Cidades, 1978.p.11-72.

QUIJANO, A. Redefinición de la dependencia y proceso de marginalización social. In: WEFFORT, F., y QUIJANO, A. Populismo, marginalización y dependencia. Ensayos de interpretación sociológica, San José, Costa Rica, Universidad Centroamericana, 1973, pp. 180-213.

ROSANVALLON, P. A nova questão social: repensando o estado providência. Brasília, DF: Instituto Teotônio Vilela, 1998. 170p.

UGÁ, V. D. A categoria "pobreza” nas formulações de política social do Banco Mundial. Revista de Sociologia e Política, v.23, p.55-62, 2004.

UGÁ, Vívian, D. A questão social como "pobreza": crítica à conceituação neoliberal. Tese [Doutorado em Ciência Política] - Instituto Universitário de Pesquisa do Rio de Janeiro, Rio de Janeiro, Rio de Janeiro, 2008. 232p.

VÉRAS, MPB. Prefácio à edição brasileira. IN: PAUGAM, S. Desqualificação social: ensaio sobre a nova pobreza. São Paulo: Educ/Cortez, 2003. p.13-29.

WACQUANT, L. L'underclass urbaine dans l'imaginaire social et scientifique américain. IN: PAUGAM, S. (orgs) L'exclusion: l'etat des savoirs. Paris: La Décourverte, 1996. p.248-262. 
WACQUANT, L. The Militarization of Urban Marginality: Lessons from the Brazilian Metropolis. International Political Sociology, v.2, p.56-74, 2008.

WACQUANT, L. Urban Marginality in the Coming Millennium. Urban Studies, v. 36, n. 10, p.1639-1647, 1999.

WANDERLEY, M. B. Refletindo sobre a noção de exclusão. In: SAWAIA, op. cit, 2004. p.16-26.

WATT, P. Urban Marginality and Labour Market Restructuring: Local Authority Tenants and Employment in an Inner London Borough. Urban Studies, v. 40, p. 1769-1789, 2003.

XIBERRAS, M. As teorias da exclusão: para uma construção do imaginário do desvio. Lisboa:Instituto Piaget, Portugal, 1996. 251p.

ZALUAR, A. Exclusão e políticas públicas: dilemas teóricos e alternativas políticas. Rev. bras. Ci. Soc., v.12, n.35, p.29-47, 1997.

ZALUAR, A. M. A máquina e a revolta. São Paulo : Brasiliense; 1985. 265p.

ZALUAR, A. M. Integração perversa: pobreza e tráfico de drogas. Rio de Janeiro: Fundação Getúlio Vargas, 2004. 438p.

ZIONI, F. Exclusão social: noção ou conceito? Rev. Saúde \& Sociedade, v.15, n.3, p.15-29, 2006.

\section{Notas}

1 "Embora nem sempre reconhecido, o debate latino-americano sobre a marginalidade prenunciava as preocupações atuais com a exclusão social" (tradução livre).

${ }^{2}$ As autoras participaram igualmente em todas as etapas da elaboração do artigo. 
Marginal Mass in Latin America: changes in how poverty is conceptualised and addressed 40 years after the theory

Approaches to, and expressions of, social issues as poverty involve discussing how social fractures connected with the process of capitalist restructuring are shaped and to be addressed in several dimensions (economic, political, cultural and social). This paper aims to review this debate 40 years after Jose Nun's marginality theory turned a fresh eye to Latin American poverty. It highlights singularities over that period in ways of looking at poverty as a social issue in Latin America and the approximation with French theorists of social exclusion. After the 1990's the debate is steered by the theoretical perspective of social exclusion, operationalised as a category capable of revealing the weakening and breakdown of social cohesion in terms of multiple levels and relational dimensions.

Key words: poverty; social inequity; social sciences. 